Meta

Journal des traducteurs

Translators' Journal

\title{
Traduire le vocabulaire juridique français en roumain
}

\section{Gabriela Scurtu}

Volume 53, numéro 4, décembre 2008

URI : https://id.erudit.org/iderudit/019653ar

DOI : https://doi.org/10.7202/019653ar

Aller au sommaire du numéro

\section{Éditeur(s)}

Les Presses de l'Université de Montréal

ISSN

0026-0452 (imprimé)

1492-1421 (numérique)

Découvrir la revue

Citer cet article

Scurtu, G. (2008). Traduire le vocabulaire juridique français en roumain. Meta, 53(4), 884-898. https://doi.org/10.7202/019653ar

\section{Résumé de l'article}

Le discours juridique est un type de communication spécialisée singularisé par un ensemble de traits qui tiennent autant à l'existence d'un vocabulaire spécialisé qu’aux particularités de sa structure discursive. Dans le cas pris en considération, celui des textes normatifs, nous nous sommes proposée de mettre en évidence un faisceau de traits pertinents pour leur structuration linguistique, portant sur ce que les auteurs en jurilinguistique considèrent comme le premier obstacle à la communication juridique - le lexique. Nous y relevons des problèmes spécifiques à la traduction juridique, plus précisément les problèmes soulevés par les différentes catégories de termes établies à l'intérieur de ce qu'on peut appeler de façon générique " vocabulaire juridique " : les mots d'appartenance juridique principale, les mots à double appartenance, le vocabulaire de soutien et les collocations. 


\title{
Traduire le vocabulaire juridique français en roumain
}

\author{
GABRIELA SCURT U \\ Université de Craïova, Craïova, Roumanie \\ g_scurtu@yahoo.com
}

\begin{abstract}
RÉSUMÉ
Le discours juridique est un type de communication spécialisée singularisé par un ensemble de traits qui tiennent autant à l'existence d'un vocabulaire spécialisé qu'aux particularités de sa structure discursive. Dans le cas pris en considération, celui des textes normatifs, nous nous sommes proposée de mettre en évidence un faisceau de traits pertinents pour leur structuration linguistique, portant sur ce que les auteurs en jurilinguistique considèrent comme le premier obstacle à la communication juridique - le lexique. Nous y relevons des problèmes spécifiques à la traduction juridique, plus précisément les problèmes soulevés par les différentes catégories de termes établies à l'intérieur de ce qu'on peut appeler de façon générique «vocabulaire juridique»: les mots d'appartenance juridique principale, les mots à double appartenance, le vocabulaire de soutien et les collocations.
\end{abstract}

\begin{abstract}
The legal discourse represents a variety of specialized communication characterized by several distinctive characteristics, originating both in the existence of a specific vocabulary, but also in the discursive particularities inherent to this type of communication. In discussing normative texts, in this article, we are going to focus on a set of features which are representative of the particular linguistic structure of such texts. These features currently affect what the specialists in legal linguistics consider to be the primary obstacle to any type of legal communication - the lexis. We shall therefore underscore the problems specific to the different categories defined within the so-called "legal vocabulary": words belonging primarily to the legal field, words that belong to two different fields, as well as the support vocabulary and collocations.
\end{abstract}

\section{MOTS-CLÉS/KEYWORDS}

discours juridique, texte normatif, vocabulaire juridique, vocabulaire de soutien, collocation

\section{Introduction}

La langue juridique est l'une des langues de spécialité les plus complexes. Ses éléments constitutifs sont, selon Gémar, le sens, la syntaxe, le lexique et le style, dont le premier serait «le plus impénétrable» (1991: 276).

Sa traduction est donc complexe elle aussi, car les difficultés procèdent fondamentalement du caractère contraignant du texte juridique. Ce caractère lui est attribué par la norme de droit. Traduire des textes juridiques signifie reconnaître les éléments juridiques et linguistiques qui ont façonné la norme de droit et les transposer dans une autre langue et dans une autre culture. C'est une tâche qui laisse au traducteur une marge de manœuvre assez restreinte quant au choix des ressources linguistiques. Lerat souligne à cet égard que «les principales difficultés 
de la traduction juridique sont les dénominations, les constructions et les compatibilités sémantiques» (2002: 155).

À l'heure actuelle, en Roumanie, les intervenants du domaine juridique disposent, malheureusement, de trop peu d'outils conceptuels issus des recherches et des réflexions menées dans ce domaine. Pourtant, les universités roumaines offrent aujourd'hui une formation en terminologie et traduction juridiques, surtout en vue de former des traducteurs spécialisés, capables de préparer la documentation exigée dans la perspective de l'intégration des pays de l'Est dans l'Union européenne.

Dans le cadre esquissé, nous nous proposons de discuter certains problèmes de traduction soulevés par les textes normatifs français ${ }^{1}$ (textes qui ont pour vocation d'exposer les règles de conduite, les obligations et les droits de diverses catégories de populations - les sujets de droit -, qu'il s'agisse des citoyens d'un État ou de catégories plus larges encore, dans le cas du droit communautaire).

Le but de cet article est de mettre en évidence un faisceau de traits pertinents pour la structuration linguistique des textes normatifs, portant sur ce que les auteurs en jurilinguistique considèrent, non sans raison, comme le premier obstacle à la communication juridique, à savoir le lexique.

\section{Catégories de termes et types de difficultés lexicales}

Une caractéristique immédiatement observable de la langue juridique réside dans le phénomène d'opacité. Nous citons à cet égard Sourioux et Lerat: «[...] le droit est un phénomène aussi largement social que la langue elle-même, mais qui suscite un sentiment d'étrangeté chez le plus grand nombre» (1975: 10). En effet, la communication du droit se heurte à un véritable écran linguistique, se situant en dehors du circuit naturel d'intercompréhension qui caractérise les échanges linguistiques ordinaires entre les membres d'une communauté linguistique donnée. À cette impression concourent, peut-être à égale mesure, le lexique (avec tout ce que ce terme implique) et la «juridicité» des énoncés.

$\mathrm{Au}$ sein de ce qu'il est d'usage d'appeler avec un terme générique «vocabulaire juridique», nous avons établi plusieurs catégories de termes et de structures lexicales qui seront envisagées sous l'angle de leur traduction vers le roumain. Selon Gémar (1991 : 276), la structure d'un discours spécialisé, en l'occurrence du droit, pourrait être représentée par une série de cercles concentriques dont le premier, au centre, serait la nomenclature (la charge notionnelle des termes), suivi d'un cercle plus large qui contiendrait le vocabulaire de soutien (ou les mots cooccurrents du domaine), enfin le troisième cercle symboliserait les éléments de la langue ou les mots du vocabulaire général (articles, pronoms, verbes, adjectifs, adverbes) auxquels il faut recourir pour construire une phrase conforme aux normes de la syntaxe de la langue en question.

Notre article porte sur la nomenclature du droit, constituée de mots d'appartenance juridique exclusive et de mots à double appartenance, ainsi que sur le vocabulaire de soutien du domaine. En outre, y est abordé le problème de l'agencement des mots selon un schéma préétabli. Dans ce sens, l'étude des collocations en langue juridique s'avère d'un intérêt parfaitement justifié, car celles-ci posent de réels problèmes de traduction par leur spécificité dans chaque langue. 


\section{Les mots d'appartenance juridique exclusive}

Le vocabulaire juridique comprend tout d'abord une série de mots d'appartenance juridique exclusive (cf. Cornu 2005a: 62-68), par exemple: abrogatif, absolutoire, acquêts, cassation, comparant, déshérence, dol, greffier, irréfragable, nue-propriété, pétitoire, pourvoi, prononcé, récriminatoire, reddition, saisine, subrogation, successible, synallagmatique, testateur, etc.

Ce sont des termes techniques, employés par les initiés. Envisagés sous l'angle de la traduction en roumain, on peut en distinguer plusieurs catégories:

1. En premier lieu, les termes techniques qui ne soulèvent aucune difficulté de traduction, vu l'existence d'un correspondant direct en roumain, le plus souvent un mot emprunté au français, et qui se caractérise donc par une ressemblance formelle évidente avec le mot d'origine:

\begin{tabular}{|c|c|}
\hline $\begin{array}{l}\text { abrogatif, -ive } \\
\text { loi abrogative }\end{array}$ & $\begin{array}{l}\text { abrogativ, - ă } \\
\text { lege abrogativă }\end{array}$ \\
\hline abroger & a abroga \\
\hline abroger une loi, une disposition légale & a abroga o lege, o dispoziție legală \\
\hline absolutoire & absolutoriu \\
\hline sentence absolutoire & sentință absolutorie \\
\hline circonstances absolutoires & circumstanțe absolutorii \\
\hline dérogation & derogare \\
\hline en dérogation à... & prin derogare de la... \\
\hline dol & dol \\
\hline duplique & duplică \\
\hline impunité & impunitate \\
\hline $\begin{array}{l}\text { présomption } \\
\text { présomption d'innocence, de fraude }\end{array}$ & $\begin{array}{l}\text { prezumție } \\
\text { prezumtie de nevinovătie, de fraudò }\end{array}$ \\
\hline
\end{tabular}

2. Certains autres termes posent des difficultés de traduction, dans le sens où le terme correspondant existe, mais il n'a pas la transparence signalée plus haut:

grosse s.f.

faire une grosse

mémoire en défense

introduire un mémoire en défense

prononcé employé comme s.m.

le prononcé du divorce copie (a unui act)

a face o copie

întâmpinare

a depune o întâmpinare

pronunțare

pronunțarea divorțului

3. Enfin, pour une troisième catégorie de termes français, le roumain ne possède pas de terme simple, mais comme la réalité juridique évoquée existe, la langue fait usage d'une paraphrase explicative: 
acquêts

communauté réduite aux acquêts

ayant-droit

les ayants-droit à une prestation

comparant

les déclarations des comparants

déshérence

succession en déshérence

grossoyer

grossoyer un contrat bunuri achiziționate în timpul căsătoriei (litt. ${ }^{2}$ «biens acquis pendant le mariage»)

regim matrimonial legal (litt. «régime matrimonial légal»)

persoană care a dobândit un drept, îndreptățit (litt. "personne qui a acquis un droit»)

cei îndreptățiți la o prestație (litt. «les personnes qui ont droit à une prestation »)

(persoană) care se înfățişează / care se prezintă în fața unei autorități (litt. "personne qui se présente devant une autorité»)

declarațiile persoanelor care s-au prezentat în fața autorității judiciare (litt. «les déclarations des personnes qui se sont présentées devant l'autorité judiciare»)

lipsă de moştenitori (la o succesiune) (litt. «absence d'héritiers pour une succession») succesiune fără moştenitori (litt. «succession sans héritiers »); à relever aussi le néologisme desherență

a face o copie (a unui act) (litt. «faire la copie d'un acte») a face / a intocmi o copie a unui contract (litt. "faire / établir la copie d'un contrat»)

\section{Les mots à double appartenance}

En deuxième lieu, le vocabulaire juridique comprend des mots à double appartenance, c'est-à-dire des termes que le droit emploie dans une acception qui lui est propre. Ces termes ont au moins un sens dans l'usage courant et au moins un sens en langue juridique. Leur ensemble constitue, avec les mots d'appartenance juridique exclusive, la nomenclature du droit (la terminologie de ce domaine), noyau dur des notions fondamentales particulières à celui-ci, à partir de laquelle se réalise le discours juridique (cf. Darbelnet 1982: 51; Gémar 1991 : 275).

Au sein de cette catégorie, on peut encore distinguer (cf. Cornu 2005a: 68-87):

1. Les termes d'appartenance juridique principale

Ces termes ont un sens juridique principal et un sens extrajuridique dérivé. Ils sont donc passés dans la langue courante avec un sens secondaire, représentant de la sorte un enrichissement du français à partir du vocabulaire du droit. Ces termes constituent un trésor de mots-clés, porteurs des notions fondamentales du droit - catégories et opérations juridiques principales, actes juridiques courants, etc.: aliénation, arbitre, arbitrage, audience, autorité, avocat, caution, clause, compétence, contentieux, contestation, contrat, convention, débat, délit, gage, garantie, interdiction, héritage, héritier, justice, juge, juger, jugement, juridiction, juste, légitime, loi, magistrat, magistrature, procédure, procès, plaider, prérogative, règle, rente, requête, révocation, sanction, sentence, sursis, témoignage, témoin, testament, tribunal, tutelle, usufruit, valable, etc. 
2. Les termes d'appartenance juridique secondaire

Ces termes ont leur sens principal dans la langue courante et ont acquis, dans la langue du droit, un sens particulier.

a) Certains termes possèdent le même sens dans la langue juridique et dans la langue courante (c'est-à-dire que le droit a conservé le sens principal de la langue courante). Ils représentent les instruments essentiels de la pensée et sont mobilisés pour juger, par tous les moyens d'observation, de l'existence d'un fait, ou par tout mode de raisonnement, du bien-fondé d'une affirmation: admettre, argumenter, certitude, constatation, constater, contradiction, conviction, contredire, document, doute, énoncer, établir, exposé, exposer, négation, nier, objecter, présumer, prouver, réfutation, rejeter, supposer, supposition, etc.

b) D’autres termes entrant dans cette catégorie ont acquis dans la langue du droit un sens spécifique. Ce sont les outils universaux de la pensée analytique: abus, acte, aptitude, avantage, besoin, bien, bienfait, capacité, cause, défaut, essence, fait, forme, jouissance, matière, motif, mobile, objet, ordre, origine, profit, protection, puissance, ressources, sujet, usage, vice, volonté, etc.

Le droit puise donc abondamment dans la langue générale. Et cela constitue l'une des grandes difficultés de cette langue de spécialité: ces termes de la langue de tous les jours peuvent être dotés d'un sens différent, dans un contexte précis. Cette diversité présente la grande difficulté de ne pas être répertoriée dans son ensemble dans les divers lexiques et dictionnaires spécialisés. Les ouvrages en question n'incluent souvent que les termes du domaine proprement dit et excluent les termes de la langue courante qui, ayant acquis un sens particulier, échappent à la compréhension du néophyte.

Qu'il s'agisse de termes d'appartenance juridique principale ou secondaire, cela importe peu pour la traduction. Mais dans l'un ou l'autre cas, elle ne se résout qu'en contexte.

Par exemple adhésion trouve ses hétéronymes en roumain en fonction du déterminant que ce nom admet (1-2) ou du déterminé qui le régit (3-4):

\section{ADHÉSION}

adhésion à un parti, à une idée

adhésion de nouvelles parties contractantes

procédé d'adhésion

pays en voie d'adhésion

donner son adhésion à qqch.
1. adeziune

adeziune la un partid, la o idee

2. admitere

admitere de noi părți contractante

3. aderare

procedeu de aderare

țară în curs de aderare

4. consimțământ

a-şi da adeziunea / consimțământul la ceva

Il en est de même pour accomplissement, qui se traduit en fonction de ses déterminants: 


\section{ACCOMPLISSEMENT}

accomplissement d'un devoir, d'une formalité

accomplissement d'un projet

accomplissement d'une infraction

Arrêt se traduit à son tour par:

\section{ARRÊT}

arrêt de renvoi

arrêt de la Cour d'appel

arrêt rendu par la Cour

arrêt de mort

rendre un arrêt

prononcer un arrêt

mandat d'arrêt

jours d'arrêt

Dépôt a comme correspondants:

\section{DÉPÔT}

dépôt légal

dépôt d'une somme, d'une motion, d'un instrument de ratification

dépôt d'une demande

mandat de dépôt

Détention se traduit par:

\section{DÉTENTION}

détention d'armes

détention régulière, arbitraire, préventive détention d'un infracteur

détention d'un mineur
1. îndeplinire

indeplinire a unei datorii, a unei formalități

2. realizare

realizare a unui proiect

3. săvârşire

săvârşire a unei infracțiuni

\section{1. hotărâre, decizie}

hotărâre de trimitere

hotărâre / decizie a Curții de apel

hotărâre pronunțată de Curte

\section{2. sentință}

(sentință de) condamnare la moarte

a da o sentință

a pronunța o sentință

3. arestare, arest

mandat de arestare

zile de arest

\section{1. depozit}

depozit legal

2. depunere

depunere a unei sume, a unei moțiuni, a unui instrument de ratificare

depunere a unei cereri

mandat de depunere

\section{1. deținere}

deținere de arme

2. detenție, detențiune

detenție legală, arbitrară, preventivă

detenție a unui infractor

3. reținere

reținere a unui minor

Faute se traduit couramment par greşeală, eroare, mais, dans son sens juridique, il a pour équivalent en roumain culpă, vină: 
FAUTE

faire une faute

divorce pour faute

en cas de faute grave

faute d'omission
1. greşeală, eroare

a face o greşeală

2. culpă

divorț din culpă

in caz de culpă gravă

3. vină

vină de omisiune

C'est aussi le cas du mot lésion, pour lequel le roumain différencie le sens courant du sens juridique, par l'emploi de deux termes différents:

LÉSION

lésion d'un intérêt légitime
1. leziune (cour.)

2. lezare (jur.)

lezare a unui interes legitim

Le verbe siéger pose de nombreuses difficultés au traducteur:

\section{SIÉGER}

les juges siègent à la Cour

personne qui siège en qualité de (juge)

employé avec la préposition en

la Cour siège en comités

Le Conseil siège en différentes formations

Le Conseil siège en public
1. a-şi desfăşura activitatea (litt. « déployer son activité»)

judecătorii îşi desfăşoară activitatea la Curte (litt. «les juges déploient leur activité à la Cour») persoană care funcționează în calitate de (judecător) (litt. «personne qui agit en qualité de juge»)

2. a se constitui

Curtea se constituie în comitete (litt. «la Cour se constitue en comités»)

\section{3. a se întruni}

Consiliul se întruneşte în diferite formațiuni (litt. «le Conseil se réunit en différentes formations»)

Consiliul se întruneşte în public (litt. «le Conseil se réunit en public»)

Le problème de la polysémie de la langue juridique s'avère en effet l'un des aspects les plus difficiles à surmonter. La langue du droit est l'une des langues les plus polysémiques, un très grand nombre de termes juridiques présentant souvent, comme tous ces exemples le démontrent, plusieurs significations. Ce phénomène est d'une importance capitale et constitue selon Cornu (2005a: 92) une marque essentielle du vocabulaire juridique. Le traducteur est donc soumis à la dificulté de savoir cerner la signification précise dans le contexte donné pour trouver l'équivalent approprié en langue cible, en l'occurrence, le roumain. Comme constatation plutôt intuitive, nous pouvons retenir le fait que la riche polysémie des termes juridiques français ne se retrouve souvent plus en roumain, où elle est explicitée par l'emploi de termes différents correspondant aux différents sens du mot français équivalent.

Une autre source de difficultés réside dans le caractère archaïsant de la langue du droit. Ce trait peut se manifester à tous les niveaux du texte: du choix des termes 
jusqu'à la construction de la phrase. Le traducteur qui se trouve face à des archaïsmes doit savoir reconnaître le synonyme actuel, et, par voie de conséquence, l'équivalent roumain. Tel est, par exemple, le cas de connaître, employé dans son sens vieilli («reconnaître»), dans l'article de loi suivant:

«Dans tous les cas où un tribunal de grande instance connaîtra des actes relatifs à l'état civil [...].» (art. 54 C. civ.)
In toate cazurile in care un tribunal de mare instanță va recunoaşte acte referitoare la starea civilă [...].

Le cas du mot crime illustre des différences d'équivalence compte tenu de l'aire d'extension de ce terme, par exemple «la prévention du crime», traduit, avec justesse, par prevenirea infracțiunilor, puisque le mot crime a le sens général de «infraction grave», en plus du sens spécial de «homicide, meurtre»:

«L'exercice de ces libertés [...] peut être soumis à certaines formalités, conditions, restrictions ou sanctions prévues par la loi, qui constituent des mesures nécessaires, dans une société démocratique [...] à la défense de l'ordre et à la prévention du crime [...].» (art. 10-2 CEDH)
Exercitarea acestor libertăți [...] poate fi supusă unor formalități, condiții, restrângeri sau sancțiuni prevăzute de lege, care constituie măsuri necesare, într-o societate democratică, pentru apărarea ordinii şi prevenirea infracțiunilor [...].

Dans les exemples suivants, les noms jouissance et exercice ont été traduits tous les deux par exercitare:

"L'exercice de ces droits ne peut faire l'objet d'autres restrictions [...].» (art. 11-2 CEDH)

«'exercice de ces libertés comportant des devoirs et des responsabilités peut être soumis à certaines formalités [...].» (art. 10-2 CEDH)

«La jouissance des droits et libertés reconnus dans la présente Convention doit être assurée [...].» (art. 14 CEDH)
Exercitarea acestor drepturi nu poate face obiectul altor restrângeri [...].

Exercitarea acestor libertăți ce comportă indatoriri și responsabilități poate fi supusă unor formalități [...].

Exercitarea drepturilor şi libertăților recunoscute de prezenta convenție trebuie să fie asigurată [...].

Or, le terme jouissance est défini par le TLFi: «fait d'être titulaire d'un droit» (par exemple: la jouissance s'oppose à l'exercice d'un droit), alors que l'exercice est le fait même (l'action) d'exercer (un droit, une liberté). Pour mettre en évidence l'opposition sémantique entre les deux termes, dans le Code civil roumain, nous avons relevé le terme folosință (a unui drept), à côté de exercitare, le roumain étant dans l'incapacité d'exprimer l'idée de virtualité dans la jouissance d'un droit. D'ailleurs, dans le Projet du Code civil, on distingue nettement entre: a) capacitate de exercițiu (capacité d'exercer $=$ exercice) et b) capacitate de folosință (aptitude des personnes à avoir des obligations et des droits civils = jouissance). C'est donc un cas de modulation (emploi du concret pour l'abstrait), imposée par l'usage de la langue d'arrivée.

\section{Le vocabulaire de soutien}

Les observations rigoureuses de la linguistique juridique sont focalisées sur le domaine terminologique (le vocabulaire juridique), donc sur les mots «porteurs d'un 
sens juridique» (Cornu 2005a: 61). Darbelnet $(1979 ; 1982)$ distingue la nomenclature du droit et le vocabulaire de soutien du droit. La nomenclature comprend, comme on l'a vu plus haut, les termes appartenant à un sujet. C'est ce que Sourioux et Lerat (1975: 15) appellent «mots-bases». Mais Darbelnet suggère que le vocabulaire de soutien du droit devrait être recensé dans les lexiques et les dictionnaires spécialisés au même titre que les termes techniques. Selon cet auteur, le vocabulaire de soutien inclut les mots d'une technicité moindre ou nulle qui servent à actualiser les mots spécialisés et à donner au texte une organisation. Ce sont donc des mots usuels ou de la langue courante ayant un sens technique, que Darbelnet appelle aussi «vocabulaire para-technique», et Gémar «vocabulaire quasi juridique» (1991: 281).

Paradoxalement, pour rédiger ou traduire un texte, souvent ce n'est pas le mot technique qui constitue le problème le plus important (ces mots techniques ont fait et continuent de faire l'objet de lexicographies terminologiques). On constate, en feuilletant des répertoires de la langue juridique, que nombre de termes utilisés dans la rédaction de textes juridiques et administratifs n'ont pas été retenus. Cela est d'autant plus valable si on prend en considération la situation des dictionnaires bilingues dans le domaine. Il est vrai qu'en général les répertoires visent plutôt à la compréhension qu'à la rédaction. Au contraire, les termes du vocabulaire de soutien, bien qu'apparaissant comme marginaux, parce que transparents, s'avèrent d'un maniement plus délicat, car ils sont nécessaires pour passer de simples listes de termes au texte: c'est au moment où il faut rédiger, précise encore Darbelnet, et, en l'occurrence, complétons-nous, traduire, que ce vocabulaire prend effectivement toute sa valeur.

L'auteur précité mentionne comme appartenant au vocabulaire de soutien des mots tels que rupture (de la vie commune), entendre (un témoin), exorbiter, dépérir, supporter (au sens fiscal). Cette catégorie de termes pourrait être incluse, à notre avis, dans la classe de mots à double appartenance. À son tour, Gémar considère comme appartenant au vocabulaire de soutien «les cooccurrents du domaine» (1991: 276277), par exemple commettre dans l'énoncé Quiconque commet un délit sera puni sévèrement. Cette question reviendra ci-après lors de l'analyse des collocations rencontrées dans ce type de textes.

À notre avis, appartiennent au vocabulaire de soutien les catégories suivantes de termes:

1. Les mots à double appartenance mis à part, il reste un certain nombre de termes qui, sans avoir un sens juridique, apparaissent toutefois dans les textes avec une valeur spécifique, différente de celle qu'ils ont dans la langue «commune». Nous donnerons l'exemple de interessé et de affaire qui ne sont pas retenus dans les lexiques comme des mots d'appartenance juridique.

C'est ainsi qu'affaire n'a pas le sens qui est rendu en roumain par afacere. Dans des contextes juridiques, il se traduit par cauză ; proces:

\section{AFFAIRE}

homme d'affaires

faire des affaires

les Affaires étrangères

porter une affaire devant la Cour plaider une affaire
1. afacere om de affaceri a face afaceri, a se ocupa de afaceri Afacerile Externe, Ministerul de Externe

2. cauză; proces (litt. "cause, procès »)

a duce o cauză înaintea Curții

a pleda un proces 
À son tour, intéressé, -e, employé comme nom m.f., se traduit par persoană în cauză:

INTÉRESSÉ, -E

persoană în cauză (litt. "personne en cause») «comparution de l'intéressé à l'audience» (art. prezentare a persoanei în cauză la audiere 5-3 CEDH)

2. D’autre part, le vocabulaire de soutien comprend des formules spécifiques et des mots-outils, essentiels pour l'articulation logique du discours : en cas de, en raison de, conformément à, au titre de, en vertu de, à l'égard de, etc.

Nous ferons, dans la suite du travail, quelques remarques concernant ces deux dernières catégories de termes appartenant au vocabulaire de soutien, ainsi que les problèmes posés par leur traduction en roumain.

a. Un des éléments de la composante rhétorique consiste à employer des formules spécifiques. C'est ainsi que les textes normatifs renvoient souvent à des règles posées dans d'autres textes. De tels renvois sont introduits par des expressions spécifiques: conformément à..., en vertu de..., etc. Mais, comme il s'agit de renvois concernant exclusivement des textes, on ne rencontrera jamais de références à la pensée ou à la position d'un auteur, du type: comme le pense..., selon la thèse de.... En revanche, on pourra avoir des références impersonnelles telles que selon / d'après l'usage (le droit national, les normes internationales, etc.), en vertu des principes régissant..., étant donné que dans ces hypothèses, l'usage, les règles et les principes ont quasiment force de loi :

«[...] pour réprimer, conformément à la loi, une émeute ou une insurrection [...].» (art. 2-2 CEDH)

«En vertu du principe de coopération loyale, l'Union et les États membres se respectent et s'assistent mutuellement dans l'accomplissement des missions découlant de la Constitution.» (art. I5-2 TCE)

«Elle [la Commission] veille à l'application de la Constitution ainsi que des mesures adoptées par les institutions en vertu de celle-ci.» (art. I-26-1 TCE)

«Nul ne peut être condamné pour une action ou une omission qui, au moment où elle a été commise, ne constituait pas une infraction d'après le droit national ou international.» (art. 7-1 $\mathrm{CEDH})$
[...] pentru a reprima, conform legii, tulburări violente sau o insurecție [...].

În temeiul principiului cooperării loiale, Uniunea și statele membre se respectă şi se asistă reciproc în îndeplinirea misiunilor ce decurg din Constituție.

Comisia veghează la aplicarea Constituției, precum şi a măsurilor adoptate de către instituții în temeiul acesteia.

Nimeni nu poate fi condamnat pentru o
acțiune sau o omisiune care, în momentul
in care a fost săvârşită, nu constituia o
infracțiune, potrivit dreptului național şi
internațional.

Le texte est donc soumis à une contrainte globale de nature systémique: règles de fond et règles de forme témoignant de l'étroite solidarité entre le fond et la forme que le traducteur se doit de respecter dans le texte d'arrivée.

b. Enfin, une dernière catégorie de termes appartenant toujours au susnommé vocabulaire de soutien inclurait les mots-outils servant à exprimer les différentes articulations du texte ainsi que les diverses valeurs circonstancielles présentes dans le texte législatif, par lesquelles il est à même de fournir des précisions pouvant fixer les conditions d'application de la prescription légale. 
On peut relever de nombreuses structures préférentielles dans l'expression des relations logiques, dans le cas des deux langues:

Par exemple, pour le complément d'exception:

«Le Conseil statue à la majorité qualifiée, sauf dans les cas où la Constitution en dispose autrement.» (art. I-23-3 TCE)
Consiliul hotărăşte cu majoritate calificată, cu excepția cazului în care (litt. «à l'exception du cas où») în Constituție se prevede altfel.

Pour l'expression de la restriction:

«Il ne peut y avoir ingérence d'une autorité publique dans l'exercice de ce droit que pour autant que cette ingérence est prévue par la loi.» (art. 8-2 CEDH)
Nu este admis amestecul unei autorități publice în exercitarea acestui drept decât în măsura în care (litt. "que dans la mesure où») acest amestec este prevăzut de lege.

Pour l'expression de la condition négative:

«[...] la Commission est composée d'un nombre de membres [...] correspondant aux deux tiers du nombre d'États membres, $\dot{a}$ moins que le Conseil européen, statuant à l'unanimité, ne décide de modifier ce nombre.» (art. I-26-6 TCE)

Pour l'expression de la cause:

«Les membres de la Commission sont choisis en raison de leur compétence générale et de leur engagement européen [...].» (art. I-26-4 TCE)
Comisia este formată dintr-un număr de membri [...] care corespunde cu două treimi din numărul statelor membre, atât timp cât (litt. «tant que») Consiliul European, care hotărăşte in unanimitate, nu decide modificarea acestui număr.
Membrii Comisiei sunt aleşi pe baza (litt. «sur la base de») competenței lor generale şi a angajamentului european [...].

Comme le discours juridique fait appel à des expressions vieillies, littéraires, mais qui rehaussent le texte stylistiquement, on peut y mentionner la locution $a ̀$ raison de (expression vieillie et surannée), employée à côté de en raison de, qui est certainement l'expression usuelle:

«Les personnes qui ont perdu la nationalité française à raison du mariage avec un étranger [...].» (art. 24-2 C. Civ.)
Persoanele care au pierdut naționalitatea franceză din cauza (litt. «à cause de») / în urma (litt. «suite à») căsătoriei cu un străin.

Cette contrainte systémique (règles de fond + règles de forme inextricablement mêlés) est un des facteurs essentiels qui fondent l'autorité des textes normatifs.

\section{Les collocations}

La difficulté de la langue juridique n'est pas seulement une question de terminologie, mais aussi d'agencement des mots selon un schéma préétabli. Voilà pourquoi le dernier aspect que nous voudrions aborder est celui des collocations qui apparaissent dans ce type de textes avec une fréquence remarquable et posent des problèmes au traducteur par leur spécificité dans chaque langue. Rappelons brièvement que les collocations sont des suites de mots figés, placés en cooccurrence, dans une structure binaire et selon un statut sémiotaxique différencié (González Rey 2002: 83). L’un des 
deux lexèmes est la base ou le collocateur, l'autre est le collocatif. En principe, le sémantisme de la base reste inchangé, tandis que celui du collocatif prend généralement un sens particulier. La combinaison qui en résulte est donc partiellement compositionnelle.

Du point de vue de la traduction, les principales difficultés se situent à ce niveau intermédiaire entre le mot et la phrase, «là où tel substantif appelle normalement tel verbe ou tel adjectif dans les textes spécialisés» (Sourioux et Lerat 1975: 329).

Quant à leur typologie, les collocations sont de nature diverse, mais nous nous arrêterons à celles de base nominale et verbale.

1. Les collocations nominales posent des problèmes au niveau du collocatif:

témoins à charge/décharge - martorii acuzării/apărării (litt. «les témoins de l'accusation/de la défense»)

«[...] interroger ou faire interroger les témoins à charge et obtenir la convocation et l'interrogation des témoins à décharge dans les mêmes conditions que les témoins à charge [...].» (art. 6-3d CEDH)
[...] să întrebe sau să solicite audierea martorilor acuzării şi să obțină citarea şi audierea martorilor apărării în aceleaşi condiții ca şi martorii acuzării [...].

Dans la même classe des collocations nominales, on peut identifier des collocations terminologiques ou "phraséotermes» (c'est-à-dire les termes complexes propres à un champ de connaissances déterminé) qui s'opposent aux collocations définitoires ou "phraséotextes», c'est-à-dire la définition donnant accès à la compréhension du phraséoterme (Gréciano 1997; cité dans González Rey 2002: 92):

objecteurs de conscience et objection de conscience - la traduction est sujette à une adaptation:

«[...] tout service de caractère militaire ou, dans le cas d'objecteurs de conscience dans les pays où l'objection de conscience est reconnue comme légitime [...].» (art. 4-3b CEDH)
[...] orice serviciu cu caracter militar sau, în cazul celor care refuză să satisfacă serviciul militar din motive de conştiină, în țările în care acest lucru este recunoscut ca legitim [...]. (litt. «dans le cas de ceux qui refusent de satisfaire le service militaire pour des raisons de conscience dans les pays où ce fait est reconnu comme légitime»)

En français, on a employé une collocation terminologique, alors que le traducteur a dû faire appel à la collocation définitoire, vu que le phraséoterme équivalent manque en roumain.

2. Les difficultés de traduction relevant du mot base (ou collocateur) concernent surtout les collocations verbales:

Accomplir se traduit en roumain comme suit, en fonction du déterminant avec lequel le verbe se combine: 


\section{ACCOMPLIR}

accomplir un travail forcé

1. a executa, a efectua

a executa o muncă forțată

accomplir ses devoirs

2. a îndeplini

accomplir une tâche

a-şi îndeplini obligațiile

a îndeplini o misiune

accomplir une réforme

3. realiza, a înfăptui

a realiza o reformă

accomplir un crime

4. a săvârşi

a săvârşi o crimă

Ci-dessous sont présentés quelques exemples de collocations verbales relevées dans le corpus, avec leur équivalent en roumain:

conduire (qqn) devant l'autorité judiciaire

«Nul ne peut être privé de sa liberté, sauf dans les cas suivants et selon les voies légales: [...] s'il a été arrêté et détenu en vue d'être conduit devant l'autorité judiciaire compétente [...].» (art. 5-1c CEDH)

traduire (qqn) devant l'autorité compétente

«[...] s'il s'agit de la détention régulière d'un mineur, décidée pour son éducation surveillée, ou de sa détention régulière, afin de le traduire devant l'autorité compétente [...].» (art. 5-1d CEDH)

infliger la mort (à qqn)

«La mort n'est pas considérée comme infligée en violation de cet article dans les cas où elle résulterait d'un recours à la force rendu absolument nécessaire.» (art. 2-2 CEDH)

rendre une ordonnance

"[...] une ordonnance rendue, conformément à la loi, par un tribunal [...].» (art. 5-1b $\mathrm{CEDH})$

porter une accusation (contre qqn)

«Toute personne arrêtée doit être informée [...] des raisons de son arrestation et de toute accusation portée contre elle.» (art. 5-2 $\mathrm{CEDH})$ a aduce pe cineva în fața autorității judiciare (litt. «apporter qqn devant l'autorité judiciaire») Nimeni nu poate fi lipsit de libertatea sa, cu excepția următoarelor cazuri şi potrivit căilor legale: [...] dacă a fost arestat sau reținut in vederea aducerii sale în fața autorității judiciare competente [...].

a aduce pe cineva în fața autorității competente (litt. «apporter qqn devant l'autorité compétente»)

[...] dacă este vorba de detenția legală a unui minor, hotărâtă pentru educația sa sub supraveghere sau despre detenția sa legală, în scopul aducerii sale in fața autorității competente [...].

a cauza moartea (cuiva) (litt. «causer la mort à qqn»)

Moartea nu este considerată ca fiind cauzată prin încălcarea acestui articol în cazurile în care aceasta ar rezulta dintr-o recurgere absolut necesară la forță.

a pronunța o hotărâre (litt. «prononcer une ordonnance»)

[...] o hotărâre pronunțată, conform legii, de către un tribunal [...].

a aduce o acuzație (împotriva cuiva) (litt. "apporter une accusation»)

Orice persoană arestată trebuie să fie informată [...] asupra motivelor arestării sale şi asupra oricărei acuzații aduse împotriva sa. 
contracter mariage

«L'étranger ou apatride qui contracte mariage avec un conjoint de nationalité française peut [...], acquérir la nationalité française [...].» (art. 21-2 C.civ.)

dissoudre un mariage

"La décision qui prononce le divorce dissout le mariage à la date à laquelle elle prend force de chose jugée.» (art. 260 C.civ.)

ouvrir la tutelle «[...] le juge des tutelles peut [...] décider d'ouvrir la tutelle [...].» (art. 391 C.civ.) a încheia o căsătorie (litt. «conclure un mariage»)

Străinul sau apatridul care încheie o căsătorie cu o persoană de naționalitate franceză poate dobândi naționalitatea franceză [...].

a desface o căsătorie (litt. «défaire un mariage»)

Hotărârea care pronunță divorțul desface căsătoria la data la care ea capătă puterea lucrului judecat.

a institui tutela (litt. «instituer la tutelle») [...] instanța tutelară poate [...] hotărî instituirea tutelei [...].

Les collocations appartiennent à la langue en tant que norme. Elles sont transparentes, disponibles en bloc et apprises par cœur comme une simple unité.

En langues de spécialité, la plupart des termes complexes sont employés dans un sens littéral et n'opposent aucune résistance au décodage, mais en traduction, des problèmes surgissent visant le choix du terme juste, qu'il soit la base ou le collocatif.

\section{Conclusion}

La démarche proposée a permis de mettre en évidence le fait qu'en ce qui a trait au vocabulaire, le traducteur est soumis à des contraintes plus sévères que dans la traduction des structures phrastiques, étant donné que les mots véhiculent le sens juridique même.

La langue du droit possède, en tant que langue de spécialité, des traits qui en font une langue unique et très complexe. Son vocabulaire comprend un grand nombre de termes qui proviennent de la langue courante et de termes qui ne sauraient exister en dehors du cadre juridique.

Mais le sens que véhiculent les mots du texte, si bien choisis soient-ils, ne sera pas clairement transmis si ces mots ne sont pas agencés d'une manière précise.

La terminologie et l'agencement des mots constituent donc deux éléments du discours d'importance égale pour la signification du message.

\section{NOTES}

1. Nos quelques remarques seront faites sur des articles de la Convention des Droits de l'Homme et des Libertés fondamentales, du traité établissant une Constitution pour l'Europe et de leurs versions en roumain, ainsi que du Code civil français, pour lequel, vu l'inexistence d'un texte roumain correspondant, nous avons eu recours à des articles homologues du projet pour le Code civil roumain (les chapitres 2 et 3 du Code civil roumain, promulgué en 1865 selon le modèle du Code civil français et les dispositions du projet du Code civil italien, étant à l'heure actuelle abrogés). Le projet pour le nouveau Code civil, adopté par le Sénat de la Roumanie (2004), est né dans le contexte des profondes transformations de la société roumaine dans les années suivant l'avènement au pouvoir du nouveau régime démocratique, en décembre 1989, et des réalités européennes contemporaines qui exigeaient la promotion et la défense de nouvelles valeurs socio-morales, culturelles, économiques et scientifiques.

2. Entre chevrons est indiquée la traduction littérale des constructions roumaines. 


\section{RÉFÉRENCES}

Cornu, G. (2005a): Linguistique juridique, Paris, Montchrestien.

Darbelnet, J. (1979): «Réflexions sur le discours juridique», Meta 24-1, pp. 26-34.

Darbelnet, J. (1982): «Niveaux et réalisations du discours juridique», Langage du droit et traduction. Essais de jurilinguistique, Montréal, Linguatech et Conseil de la langue française, pp. 51-60.

FERLUŞCĂ, T. (coord.) (2004): Ghid stilistic de traducere în limba română pentru uzul traducătorilor acquis-ului comunitar, ed. a II-a, Bucureşti, Institutul European din România.

GÉmAR, J.-Cl. (1979) : «La traduction juridique et son enseignement: aspects théoriques et pratiques», Meta 24-1, pp. 35-63.

GÉmAR, J.-Cl. (1991): «Terminologie, langue et discours juridiques. Sens et signification du langage du droit», Meta 26-1, pp. 275-283.

González Rey, M. I. (2002): La phraséologie du français, Toulouse, Presses Universitaires du Mirail.

GRIDEL, J.-P. (1994): Introduction au droit et au droit français, Dalloz.

Lerat, P. (2002): «Vocabulaire juridique et schémas d'arguments juridiques», Meta 47-2, pp. 155-162.

Kerby, J. (1982): «La traduction juridique, un cas d'espèce», Langage du droit et traduction. Essais de jurilinguistique, Montréal, Linguatech et Conseil de la langue française, pp. 33-50.

Mounin, G. (1979): «La linguistique comme science auxiliaire dans les disciplines juridiques », Meta 24-1, pp. 9-17.

Schmidt-König, Chr. (2000): "La langue juridique: maux et remèdes», Frédéric Houbert, Dictionnaire des difficultés de l'anglais des contrats, Paris, pp. 117-124.

Schmidt-König, Chr. (2004): «Les difficultés du vocabulaire juridique français », International Journal for the Semiotics of Law 17, pp. 85-92.

Sourioux, J.-L. et P. Lerat (1975): Le langage du droit, Paris, PUF.

Stoıchițolu-Ichim, A. (2001): Semiotica discursului juridic, Bucureşti, Editura Universității din Bucureşti.

Toury, G. (1995): Descriptive Translation Studies and Beyond, Amsterdam, John Benjamins.

\section{Dictionnaires}

Cornu, G. (dir.) (2005b): Vocabulaire juridique, Paris, Quadrige/PUF.

Năstase, C., Ghinculov, S. et G. VÂrtosu (2001): Dicționar de economie şi drept, Bucureşti, Editura Niculescu.

SAVIN, Chr.-A. et V. SAVIN (2001): Dicționar francez-român administrativ, comercial, economic, financiar-bancar, juridic, Editura Dacia, Cluj-Napoca, Bucureşti.

Dicționarul explicativ al limbii române (DEX) (1998): Bucureşti, Editura Academiei.

Le Trésor de la langue française informatisé (TLFi), CNRS, <http: //zeus.inalf.fr/tlf.htm>.

\section{Corpus}

C. Civ. = Code Civil.

$\mathrm{CEDH}=$ Convention de sauvegarde des Droits de l'Homme et des Libertés fondamentales telle qu'amendée par le Protocole no.11, <http://conventions.coe.int/Treaty/FR/treaties/html/005. htm>.

Convenția pentru apărarea drepturilor omului şi a libertăţilor fundamentale şi protocoalelor adiționale la această convenți., $<$ http://legislatie.resurse-pentru-democratie.org/drepturi ce.php>.

TCE = Traité établissant une Constitution pour l'Europe, $<$ www.europnat.com/ce.pdf $>$.

Tratatul de instituire a unei constituții pentru Europa, <http://www.ier.ro/>. 